\title{
Design automation of load-bearing arched structures of roofs of tall buildings
}

\author{
Vladimir Kulikov ${ }^{1, *}$ \\ ${ }^{1}$ Moscow State University of Civil Engineering, Yaroslavskoye shosse 26, Moscow, 129337, Russia
}

\begin{abstract}
The article considers aspects of the possible use of arched roofs in the construction of skyscrapers. Tall buildings experience large load from various environmental factors. Skyscrapers are subject to various and complex types of deformation of its structural elements. The paper discusses issues related to the aerodynamics of various structural elements of tall buildings. The technique of solving systems of equations state method of Simpson. The article describes the optimization of geometric parameters of bearing elements of the arched roofs of skyscrapers.
\end{abstract}

\section{Introduction}

History of the issue. In 1976 at the international symposium adopted a classification based on building heights. Constructions up to $30 \mathrm{~m}$ were classified as high-rise buildings, up to 50, 75 and $100 \mathrm{~m}$, respectively, I, II and III categories of high-rise buildings, over 100 $\mathrm{m}$ to high altitude. Within this group usually resort to additional classification, gradation of height $100 \mathrm{~m}$. The number of skyscrapers over $400 \mathrm{~m}$ worldwide in less than 20 ; height from 300 to 400 no more than 50, from 200 to 300 is about 150, and buildings in height from 100 to $200 \mathrm{~m}$ - a few thousand, and the number of such buildings is growing rapidly .

In complexity, the design of tall buildings and their construction - superior to the complexity of the construction of bridges and tunnels. This is due to the repeated predominance of height over the footprint, creating a significant load on the supporting structures. The huge height of the skyscraper results in significantly superior than typical (mid-rise) building, the degree of exposure to natural factors such as solar radiation and wind load, often exceeding the total weight of the structure. The design of tall buildings is the solution of the complex of urban, climatic, geological, architectural, constructive tasks $[1,2]$.

\section{Materials and Methods}

Aerodynamics. It is obvious that for tall buildings the impact of climate, wind, air pressure changes are extreme. The first high-rise constructed of brick have not experienced such dangerous wind impact, in contrast to the modern constructions with large spans of loadbearing structures, suspended facades, arched roofs and heights. The roof structure significantly affects the aerodynamic behavior of a skyscraper. How it is possible to reduce

\footnotetext{
*Corresponding author: kulikov-miit@mail.ru
} 
the wind load? This is possible by: 1) the use of reliable structures with arched roofs, -2) thanks to the reliable methods of calculating their bearing capacity, 3) due to the limitation and reduction of levels of significance of factors affecting their aerodynamics. These provisions must be applied from the very beginning of designing tall buildings, with binding structure on the construction site in accordance with the wind rose, with the selection of the three-dimensional solution [3].

Aerodynamic load and the weight distribution of building structures vertically require, as a minimum, maintaining configuration throughout its height. From the point of view of sustainability tapering upwards more preferable. In this case, the structure occupies the entire plot, then the floor area is reduced. It can be a gradual change in the silhouette of a building on a sloping or curved lines or abrupt, blocky shape.

A rational spatial design of tall buildings. The most efficient forms of skyscrapers can be placed in a particular sequence, the degree of reducing the impact of air flow on their design. The absolute leader is the round plan. The lack of overhangs allows air to flow around the volume, without creating eddies that appear at the corners of rectangular buildings. Round plan involves the use of arched roofs. Second place belongs to the plans in the form of a derivative of circular, oval, shaped lenses or in the form of drops. Since the mid-twentieth century, more and more skyscrapers have similar plans, due to increase in their height, the optimal volume from the point of view of aerodynamics is not an artistic technique, but a necessity [4]. A transitional form, from the oval to the triangle with rounded corners is extremely popular and currently, due to its spatial rigidity. In third place - as common as a hundred years ago, square or diamond plans. This solution is the most popular for buildings above 60 floors, as they are more vulnerable to horizontal loads. In fourth place - high-rise buildings, coupled structurally or compositionally. They usually have a circular shape.

The roof is of arch type design curved shape in the form of an arc. With its help, often overlap houses, industrial or administrative structures to protect from rain, cold, wind, etc. Arched roofs are widely used in construction due to the following advantages:

1. Original appearance, which stands out from similar buildings with flat or gable roof.

2. Resistance to wind loads. The aerodynamic, curved shape with no sharp corners makes the arched roof immune to strong wind gusts which often lead to the breakdown of roofing from buildings and structures.

3. The reduction of snow load. Arch having a curved shape, does not delay the on-ramp of the snow mass, whereby the load-bearing design and construction is reduced.

4. The increase in the volume of the room. Due to the arched design of the roof increases the internal volume of buildings and structures.

The flow of air masses along the wall surfaces of buildings and structures occur with different speed, which depends on the efficiency of geometrical forms and their structural parameters, such as the arrow of the arch (its height), the span of the arch, forms the geometrical axis of the arch the cross-sectional size. When faced with an obstacle, the kinetic energy of wind is converted into pressure, creating wind load. This stress can be felt in any constructive element, is exposed to the air flow [5].

\section{Results}

The load generated by the air flow depends on the following factors: - 2) density of the air stream.(So, with high humidity, the specific gravity of air becomes greater. Therefore, increasing the value of the transferred energy); 3) the geometric shape of the stationary object (object wrapping). Based on the aspect (3), on a separate part of the building structure can influence the forces, aimed in different directions. For example: - on a vertical wall can impact a frontal force which tends to move the object. To resist this stress is the appropriate engineering design solutions, as well as the corresponding bearing capacity of the roof 
elements determined by a preliminary calculation. On the roof, in addition to horizontal efforts (indenting) can influence the vertical force generated from separation of the air flow when hitting obstacles. Vector vortex air flow tends to lift the roof up, trying to tear her away from load-bearing walls. The combination of all these eddy currents create wind load not only on the major elements of the building, but spreads its influence on all the elements of building structures. Power generated effort is usually proportional to the square calculation values of the wind speed [6].

Consider the method of calculation of forces from the respective air flows. The formalization of the calculation of values created by the efforts on vertical surfaces define a ratio:

$$
W_{m}=W_{0} \cdot k \cdot C
$$

where, $-W_{m}$ is the normative average value of wind stress at a height $h$ above the ground; $\mathrm{W}_{0}$ - normative wind pressure, depending on wind construction area, which is determined by the relevant normative document, map 3, Annex5. k-factor - coefficient of pressure fluctuations of the wind flow. C - shape factor for the façade.

So for example, for a vertical wall of a skyscraper on the ground of the construction of type (C), with the height of the object above ground level is of the order of $200 \mathrm{~m}$, the calculation will take the following initial data: $\mathrm{k}$-factor $=0,84$; (IV) area of construction, normative wind pressure $\mathrm{W}_{0}=48 \mathrm{~kg} / \mathrm{m}^{2}$. The shape factor for the flat facade $\mathrm{C}=0,8$. Created by stress on $1 \mathrm{~m}^{2}$ will be:

$\mathrm{W}_{\mathrm{m}}=\left(48 \mathrm{~kg} / \mathrm{m}^{2} \times 0,84 \times 0,8\right)=32,256 \mathrm{~kg} / \mathrm{m}^{2}$

At the height of the wall in the 200 meters and width 30 meters total wind load is: (200 $\mathrm{m} \times 30 \mathrm{~m} \times 32,256 \mathrm{~kg} / \mathrm{m}^{2}$ ) $=193536 \mathrm{~kg}$ or 193,536 tons, i.e. significant value. For other areas of the building, the estimated value may change in one direction or another.

Most of the damage with strong gusts of wind associated with the design of the roof. There are many good examples of how not only the individual elements of the roof, but entire roof breaks under the influence of the wind load. In a frontal direction of the wind is a collision of the wind from the front of the building and roof. Next to the vertical surface of the roof the air flow creates a vortex multidirectional vectors, in this case - there is a division on the lower, lateral and vertical components of the wind. The lower direction is the safest for the building, as all efforts are directed in the direction of the Foundation, i.e. in the direction of one of the most durable and massive parts of the structure [7,8]. Lateral components affect the facade of the building. Vertical air flow stream at the same time aimed directly at the eaves and creates a lifting force tending to lift the roof up and move it. The air flow is directed to the slope of the roof forms a tangential direction, sliding along the roof, enveloping the upper girder (roof ridge) and going away. This force also tends to move the roof. The perpendicular force is the normal directed inside of the roof, creating pressure, indenting the roof elements into the structure. On the leeward side of the roof, - creates an opposite force that helps create lift. Adding together all the direction of air flow, you can see that, with a high sloping roof formed efforts seeking to overturn the roof. A gentle slope helps to create large lifting forces which try to lift the design and send it in free flight. Calculation of the air load on the roof depending on the height of its location above ground level, will produce according to the formula:

$$
W_{p}=0,7 \cdot W \cdot k \cdot C
$$

$W$ - the standard value of the force generated by air pressure. Is determined by the maps in the Annex to the normative documents; $k$ - coefficient showing the pressure dependence of the height above the section of the upper ground level. $C$ - aerodynamic factor, taking into account the direction of airflow on the roof. The positive value of the aerodynamic coefficient means that the wind pushes directly on the surface. Negative values flow creates a vacuum at the surface of the roof, in other words, the "suction" of air cushion. 
So for example, suppose the building is located on the shore of a large internal reservoir, and the area is of type (A). The roof is located at an altitude of $200 \mathrm{~m}$, then the coefficient $k=2,45$. The prevailing winds are directed into the gable roof. The aerodynamic figure for roofs with a slope of $\alpha=30^{\circ}=-1,4$. The norm for this area of construction $W=53 \mathrm{~kg} / \mathrm{m}^{2}$. Estimated value of the wind stress will be:

$$
W_{p}=0,7 \times 53 \mathrm{~kg} / \mathrm{m}^{2} \times 2,45 \text { хэ }(-1,4)=-127,253 \mathrm{~kg} / \mathrm{m}^{2}
$$

A negative value indicates that there is a force tending to tear the roof of the building. If the roof area of $\mathrm{S}=120 \mathrm{~m} 2$, the total force will be: $\mathrm{P}=120 \mathrm{~m} 2 *(-127,253 \mathrm{kgf} / \mathrm{m} 2)=-$ $15270,36 \mathrm{kgs}$, about 15,253 tons..

\section{Discussions}

Conclusion 1. On high-rise buildings a significant and dangerous impact has the environment, atmosphere, humidity and ambient pressure. These impacts represent a number of poorly predictable alternating, and randomly alternating loads on skyscrapers. However, the article presents a modern and reliable methods to calculate their impact.

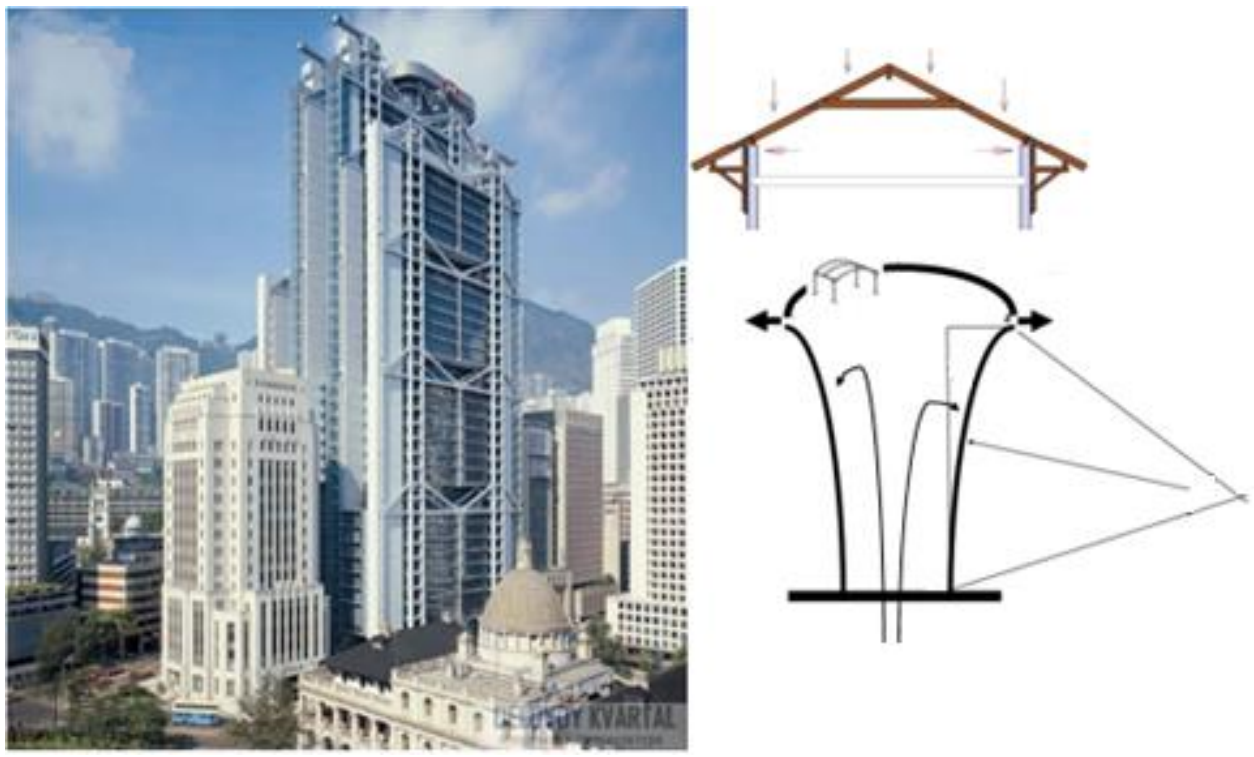

Fig.1 Possible deformation of the vertical walls of the skyscraper due to the impact of uncompensated thrust of the arched roof.

Calculate the arch of the roof of a skyscraper, is shown in Fig.1 (a) method of forces. We introduce the notation for the possible deformations of structural elements of the arched roof, fig. (b) in the following way:

$$
\delta_{\mathrm{ij}} \cdot \mathrm{x}_{\mathrm{i}}+\Delta_{\mathrm{ip}}=0
$$

Where $\delta_{i i}=-$ movement from unit loads, $\Delta_{i p}$ - movement from cargo loads.

$$
\begin{aligned}
\Delta_{i p} & =\int_{S} \frac{m \cdot M_{p}}{E \cdot J} d S+\int_{S} \frac{n \cdot N_{p}}{E \cdot F} d S+\int_{S} \frac{q \cdot Q_{p}}{E \cdot G} d S \\
\delta_{i i} & =\int_{S} \frac{m_{i} \cdot m_{j}}{E \cdot J} d S+\int_{S} \frac{n_{i} \cdot n_{j}}{E \cdot F} d S+\int_{S} \frac{q_{i} \cdot q_{j}}{E \cdot G} d S
\end{aligned}
$$

Refer to fig.2, which show a virtual fragment of the arch length $(d s)$ of the roof shown in fig. 1 (c). Show system global $\left(x^{\prime} 0 y^{\prime}\right)$ and local $(x O y)$ coordinates. Using $(d x)$ and $(d y)$ denote the projection $(d s)$ to the corresponding axes $0 x^{\prime}, 0 y^{\prime}$. 


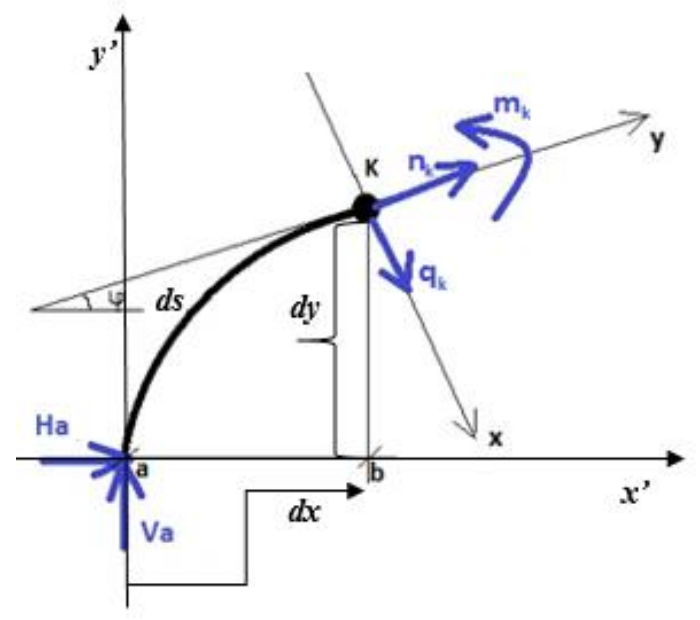

Fig.2. Detail of the arch of the roof of a skyscraper.

From fig.1, with a certain degree of accuracy, it is obvious that:

$$
d S \cdot \cos (\varphi)=d x \rightarrow d S=\frac{d x}{\cos (\varphi)}
$$

Substitute (6) into (4) and move from the integration curve integral along the entire length of the arch (ds) fig.2, for integrating (dx) on certain selected sites (x1x2) of the arch considered in fig.1(c):

$$
\Delta_{i p}=\int_{x 1}^{x 2} \frac{m \cdot M_{p}}{E \cdot J \cdot \cos (\varphi)} d x+\int_{x 1}^{x 2} \frac{m \cdot \cos (\varphi) \cdot N_{p}}{E \cdot F \cdot \cos (\varphi)} d x+\int_{x 1}^{x 2} \frac{m \cdot \sin (\varphi) \cdot Q_{p}}{E \cdot G \cdot \cos (\varphi)} d x
$$

Write the equation of the geometrical axis of the arch is calculated as $y(x)=\frac{f \cdot x(2 \cdot l-x)}{l^{2}}$ where $(f)$ is the height of the arch, and $\mathrm{l}=(1 / 2)$ the span of the considered arch.

Bearing in mind that $m=\frac{y(x)}{f}=\frac{f \cdot x(2 \cdot l-x)}{l^{2}}$, we get:

$$
\begin{gathered}
\Delta_{i p}=\int_{A}^{B} \frac{m \cdot M_{p}}{E \cdot J \cdot \cos (\varphi)} d x=\int_{A}^{B} \frac{x \cdot(2 \cdot l-x) \cdot M_{p}}{E \cdot J \cdot \cos (\varphi) \cdot l^{2}} d x \\
\delta_{11}=\int_{A}^{B} \frac{m^{2} d x}{E \cdot J}=\int_{A}^{B} \frac{\left(\frac{x \cdot(2 \cdot l-x)}{l^{2}}\right)^{2}}{E \cdot J} d x=\int_{A}^{B} \frac{x^{2} \cdot(2 \cdot l-x)^{2}}{E \cdot J \cdot l^{4}} d x
\end{gathered}
$$

Using the conversion expression (3) can be represented as follows:

$$
\delta_{\mathrm{ij}} \cdot \mathrm{x}_{\mathrm{i}}+\Delta_{\mathrm{ip}}=0 \rightarrow x_{i}=-\frac{\Delta_{i p}}{\delta_{i j}}=-\frac{\int_{A}^{B \frac{x \cdot(2 \cdot l-x) \cdot M}{E \cdot J \cdot \cos (\varphi) \cdot l^{2}}} d x}{\int_{A}^{B x^{2} \cdot(2 \cdot l-x)^{2}}}
$$

For the taking of the integrals presented in (10), we have the formula (11) Simpson method:

$$
I=\frac{h}{3} \cdot\left[f\left(x_{0}\right)+f\left(x_{n}\right)+4 \cdot\left(\sum f\left(x_{\text {odd }}\right)\right)+2 \cdot\left(\sum f\left(x_{\text {even }}\right)\right)\right]
$$

Conclusion 2. A significant influence of environmental factors on high-rise buildings leads to large internal stresses in various structural elements of skyscrapers. The article presents the method of calculation of the structural deformation of the arched roof of a skyscraper. This article uses the modern methods of choice of materials of construction and cross sections sufficient to prevent their destruction from extreme loads.

Formalize the notion of "Rational axis of the arch". The rational axis of the arch of a given span and a given rise. we will call such an axis in which the cross section of the arch required by the conditions of strength will be the smallest. Reducing the transverse 
dimensions of the arch is associated with a decrease of the actual voltage which the arc is defined by the formula:

$$
\sigma=\frac{N}{F}+\frac{M}{I} \cdot y
$$

It is obvious that the lowest value of the actual stress will be the case when the value of the bending moment in the cross section will be zero. The last statement will be true in the case that the resultant of the internal forces will pass through the center section. This condition needs to satisfy all sections of the arch, and this is equivalent to saying that the rational axis of the arch should coincide with the pressure curve. The construction of the pressure curve associated with a given distribution of the cross section of the arch. This situation greatly complicates the analytical study of matter. Therefore, the study of the question of the rational axis of the arch to produce on conventional, so-called "delicate" arch, with no real cross sizes. In this arch the curve of pressure coincides with a virtual curve for a given load. Errors that are taking place at such consideration, usually small, and their influence on the contour of the axis of the real arch can be neglected. The virtual curve depends on the size and location of the load. Position it in the arch completely determined by three points, beginning, middle, and end. But the change of its position between these points depends on the location of the load along the length of the arch.

Assume that arch is subjected to vertical external load. Mentally cutting out the arch element of length (ds), and given the fact that by combining the axis of the arch with the virtual curve, moment and shear force in its cross-section must be zero. We balance the element of two normal forces $(\mathrm{N})$ and $(\mathrm{N}+\mathrm{dN})$. As mentally the cut element under the action of applied thereto of forces is in equilibrium, we can write the following equation:

$$
N \cdot \sin \left(\frac{d \varphi}{2}\right)+(N+d N) \cdot \sin \left(\frac{d \varphi}{2}\right)-q_{z} \cdot d x \cdot \cos (\varphi)=0
$$

Because of the smallness of the angle $(d \varphi)$ can be taken that $\sin \left(\frac{d \varphi}{2}\right)=\left(\frac{d \varphi}{2}\right)$. Value of $\left(d N \frac{d \varphi}{2}\right)$ as an infinitesimal of the second order can also be neglected. $d x=d s \cdot \cos (\varphi)$. Under these conditions, equation (13) can lead to the next view

$$
N \cdot d \varphi=q_{z} \cdot d s \cdot \cos ^{2}(\varphi)
$$

If, under the action of external vertical loads on an arch projection on the horizontal normal force in all sections of the arch is equal to the thrust $N \cdot \cos (\varphi)=H$, equation (14) can be transformed to the following form:

$$
\begin{gathered}
\frac{d \varphi}{d s}=\frac{q_{x} \cdot \cos ^{2}(\varphi)}{H} \\
\frac{d \varphi}{d s}=\frac{1}{\rho}=\frac{y^{\prime \prime}}{\sqrt{\left(1+y^{\prime 2}\right)^{3}}}
\end{gathered}
$$

Using the (16) ratio, substituting the relevant expressions and $(\cos (\varphi), d \varphi, d s)$ in equation (15) and making some transformation, obtain the differential equation of the effective axis of the arch when subjected to consider the arch of the external vertical load:

$$
y^{\prime \prime}= \pm \frac{q_{x}}{H}
$$

The sign in this equation should be chosen according to the location of the center of curvature along the coordinate axes. If the center of curvature is on the side of positive $y$, the plus sign, if negative ordinate, a minus.

$$
y=\frac{q \cdot x \cdot\left(2 \cdot l_{1}-x\right)}{2 \cdot H}
$$


Conclusion 3. The article presents the method of optimization of geometrical parameters of the bearing element of the roof of a skyscraper, the arch. The use of this technique in the real design will significantly reduce the influence of external destructive factors on the structural elements of skyscrapers.

\section{Conclusion}

Taking into account the conclusions 1, 2, 3 can say with certainty about the possibility of using arched roofs in the design and construction of skyscrapers.

\section{References}

1. I.V. Ilin, A.I. Levina, O.Yu. Iliashenko, MATEC Web of Conf, 86, 05028 (2016) doi $10.1051 /$ matecconf $/ 20168605028$

2. A. Ilin, O. Kalinina, O. Iliashenko, A. Levina, Procedia Engineering, 165, 1673- 1682 (2016) DOi - 10.1016/j.proeng.2016.11.909

3. O. Kalinina, O. Valebnikova, Advances in Intelligent Systems and Computing, $\quad 692$, 1315-1322 (2018) DOi - 10.1007/978-3-319-70987-1_139

4. A. Zaychenko, S. Gutman, O. Kalinina, Advances in Intelligent Systems and Computing, 692, 453-462 (2018) DOi - 10.1007/978-3-319-70987-1_48

5. T.A. Emelyanova, A.P. Denisova, Sarat. GOS. tehn. University (2013) ISBN 978-57433-2666-2.

6. T.G. Maklakova, Design of civil buildings: Proc. settlement (Stroyizdat, Moscow, 2013)

7. N.G. Vilchik, The architecture of the buildings: the textbook (INFRA-M, 2012)

8. V. Kankhva, Procedia Engineering, 165 (2016) doi:10.1016/j.proeng.2016.11.855 